\title{
Understanding the evolution of nuclear waste repositories by performing appropriate experiments - selected investigations at Mont Terri rock laboratory
}

\author{
Kristof Schuster, Markus Furche, Hua Shao, Jürgen Hesser, Jan-Martin Hertzsch, Werner Gräsle, and \\ Dorothee Rebscher \\ Federal Institute for Geosciences and Natural Resources, BGR, Stilleweg 2, 30655 Hannover, Germany
}

Correspondence: Kristof Schuster (kristof.schuster@t-online.de)

Received: 29 May 2019 - Revised: 8 September 2019 - Accepted: 1 October 2019 - Published: 30 October 2019

\begin{abstract}
Any site selection process for a final repository for high-level and heat producing radioactive waste is a national challenge and has to take into account, among others, regional geological settings. In Germany, the site selection has to restart from zero, and all potential host rocks have to be considered equal, including argillaceous rocks. Therefore, the Federal Institute for Geosciences and Natural Resources (BGR) performs appropriate experiments in the Swiss Mont Terri rock laboratory, which is located in the Jurassic Opalinus Clay. In this paper, activities and results from actual and still ongoing experiments, with participation of BGR, are presented exemplarily. All experiments aim for a contribution to understand particular aspects regarding the behaviour of underground facilities, BGR's focus lies mainly on aspects of the early lifetime of a repository, namely the construction, post-closure transient, and partly post-closure equilibrium phases. It is obvious that for a full understanding of the evolution of a final repository, knowledge and experience of many different groups, their studies and results covering all aspects, have to be included. In this paper, we can only emphasise a few representative examples on geophysical and geotechnical in-situ site investigations, geotechnical mine-by monitoring, laboratory investigations, and modelling aspects. The combined interpretation of these results enhance interpretations and is a prerequisite for a comprehensive understanding of a repository.
\end{abstract}

\section{Introduction and motivation}

Understanding all the relevant processes which are characteristic during the whole lifetime of a final repository for heat producing high-level radioactive waste (HLW) is an extraordinary challenge that cannot be achieved by a single group or one institution alone. Obviously, it has to be addressed in close collaboration with many qualified partners, each providing their particular experience, in order to include all aspects for the full understanding of a HLW, hence, benefitting from the specialised knowledge of these partners. This approach for the realisation of repositories has to be pursued, worldwide. Establishing a final repository starts with a site selecting processes. However, this is not discussed in the present paper. Here, the focus lies mainly on relevant HLW investigation methods and results. BGR has gained long-standing competence related to final repositories and experience by performing different experiments in national and international underground facilities. As claystone is one of the three potential host rocks for a HLW-repository in Germany, BGR - as the central geoscientific authority providing advice to the German Federal Government in all geo-relevant questions - has performed suitable and qualified experiments in the Opalinus Clay (age about $174 \mathrm{Ma}$ ) at the Mont Terri rock laboratory in Switzerland. Since the establishment of the Mont Terri Project (MTP) in 1996, BGR is an active partner in the consortium. With the continuous growth of MTP, there will be 21 partner organisations from nine countries by July 2019 (swisstopo, 2019).

Figure 1 depicts the two key parameters, i.e. temperature and water saturation, which dominate the evolution of a 
final repository in an argillaceous formation, and their development over the first hundred thousand years of the repository life time. Furthermore, main evolution steps are indicated, combined with the acronyms of more than 60 experiments. These experiments are performed at the Mont Terri rock laboratory by the various partners in order to enhance the understanding of all phases, starting from construction and emplacement to post-closure processes and final radionuclide transport. BGR is mainly involved in the earlier phases (indicated in green tones); corresponding experiments are referred to in the text.

While all partners perform their own specialised experiments, they do so in close collaboration and continuous exchange in order to avoid doubling and for mutual benefit. This ensures that all results and experiences are available immediately to the partners, becoming later open to the general scientific community. In this context, BGR covers a complete chain of experiments, supporting the comprehensive understanding of the complex material behaviour of the Opalinus Clay (refer Fig. 2). The interconnected sub-aspects start from high resolution geophysical and geotechnical in-situ site characterisation, including certified drilling, core sampling, as well as conditioning, transport, and laboratory testing up to the complex modelling of dynamical processes with thermal, hydrological, mechanical, and chemical coupling.

The experiments cover the full evolution of a HLWrepository, i.e. spanning a time period of up to one million years. Experiments which are discussed in this paper are representative for the first periods of the evolution (one to several thousands of years). This comprises the construction period (desaturation), the canister emplacement (temperature pulse) period, the post-closure transient phase (decrees of temperature, ongoing re-saturation), and the post-closure equilibrium phase. For the said purposes, the Mont Terri rock laboratory offers an excellent platform to perform the required experiments.

In Fig. 3, the layout of the Mont Terri rock laboratory displays the section, which was excavated until 2012 and the extension of the laboratory, which started end of 2018 and will be finished in late autumn 2019. In addition, Fig. 3 illustrates the main facies of the Opalinus Clay encountered in the laboratory, i.e. the shaly, sandy, and carbonate-rich sandy facies. With this considerable extension (in green), more experiments can be performed in the sandy facies (in beige colour) and as a novelty in the transition to the Passwang Formation (in light blue).

\section{Selected experiments and results}

In this paper, we focus exemplarily on some selected aspects of our more than 20 years of work at the Mont Terri rock laboratory, presenting some major achievements and results, which are used by internal and external partners for mutual enhancement of interpretation. All presented data, results, and interpretation stem from experiments conceptualised, performed, and interpreted by the authors. In each chapter, a short first interpretation of the presented results are given whereas an overall discussion will be given at the end.

\subsection{Geophysical in-situ site investigations}

After a site selection process, one of the first steps is an in-situ site characterisation of the potential repository. BGR developed different geophysical tools with very high spatial and dynamic resolutions, which allow for precise characterisation of the rock. The preferably applied MiniSeismic Methods (MSM) are described in detail in Schuster et al. (2017) and Schuster (2019), whereas Electrical Resistivity Tomography (ERT) methods are described in Schuster and Furche (2016). In order to achieve high resolution data, boreholes are used and Interval Velocity Measurements (IVM) are applied. They provide parameters like seismic Pand $\mathrm{S}$-wave velocities $\left(v_{\mathrm{p}}, v_{\mathrm{s}}\right)$ and dynamic Young's modulus $\left(E_{\mathrm{dyn}}\right)$. This in turn allows the characterisation of Excavation Damaged/disturbed Zone (ED/dZ) features at different stages of the evolution and in a more general context, it contributes to an assessment of the geo-mechanical site-situation. Moreover, long-term monitoring studies of emplacement experiments are performed, which are of high relevance for the assessment of barrier integrity. Results from four experiments are presented in the following

Within the WS-I-experiment (investigation of wet spots), different methods were applied in the same borehole: MSM, ERT, Optical Televiewer (OPTV), Gamma Ray, and conventional induction log measurements (Schuster and Furche, 2016). Figure 4 presents results from an $8 \mathrm{~m}$ long part of the borehole. For both MSM and ERT, a measurement step of $5 \mathrm{~cm}$ was chosen. It is evident that in general a very good correlation exits between apparent seismic velocity $v_{\mathrm{p}}$ (blue line), electrical resistivity (green line), and the derived Gamma Ray Index (GRI, red line). In comparison to the observed GRI, the conventional induction log (indicated in black) follows the main structures without showing the small-scale variations. We interpret regions featuring higher values for $v_{\mathrm{p}}$ and electrical resistivity to lithological layers of higher carbonate content and vice versa. However, in some cases, a negative correlation can be seen (e.g. at $7 \mathrm{~m}$ in Fig. 4). The light grey layer in the OPTV implies a higher carbonate content, which seems to be in contradiction with the relatively low resistivity ERT findings and the associated interpretation in respect to the composition of the matrix rock. Further investigations have to be conducted to explain the observations.

As part of the laboratory extension, measurements using MSM and ERT were performed in three exploration boreholes (BPE), confer Fig. 3. Some results from borehole BPE-2 (Fig. 3, red line) are presented in Fig. 4. The borehole is oriented normal to bedding strike and hits the bedding 


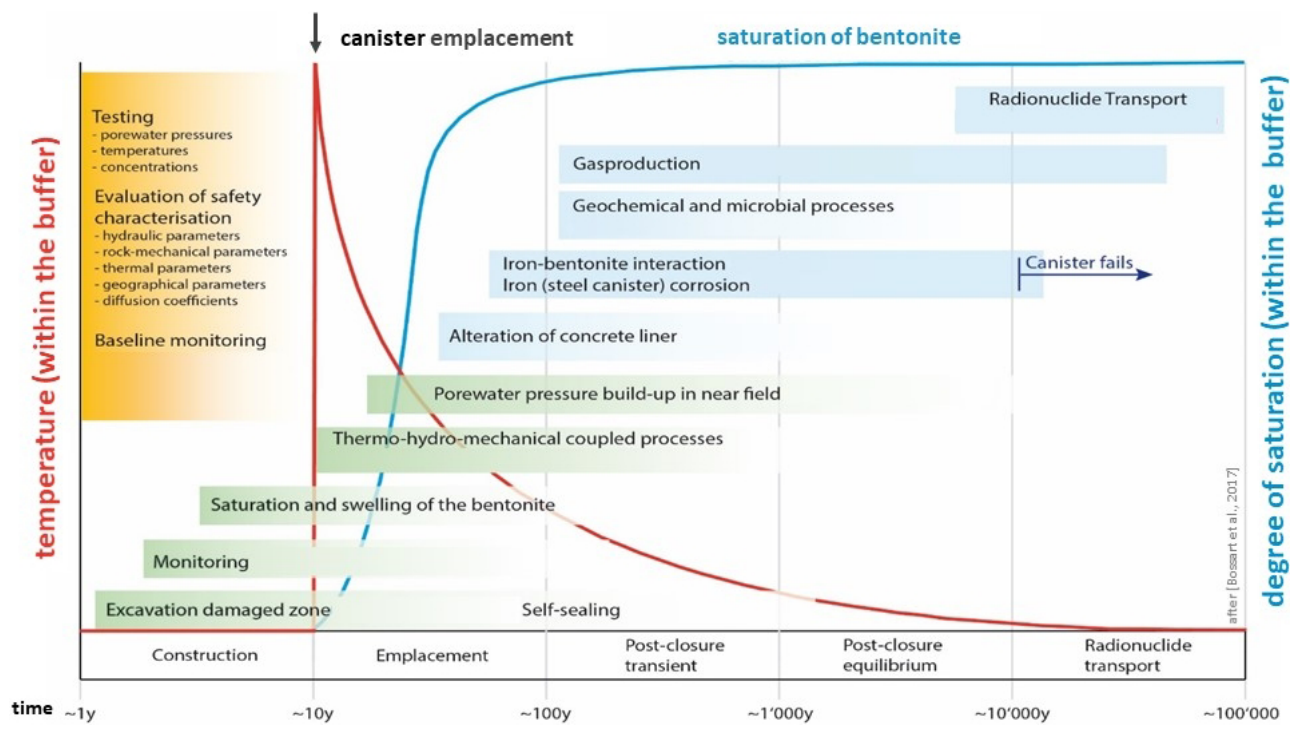

Figure 1. Temporal evolution and implications for a nuclear waste repository after Bossart et al. (2018).

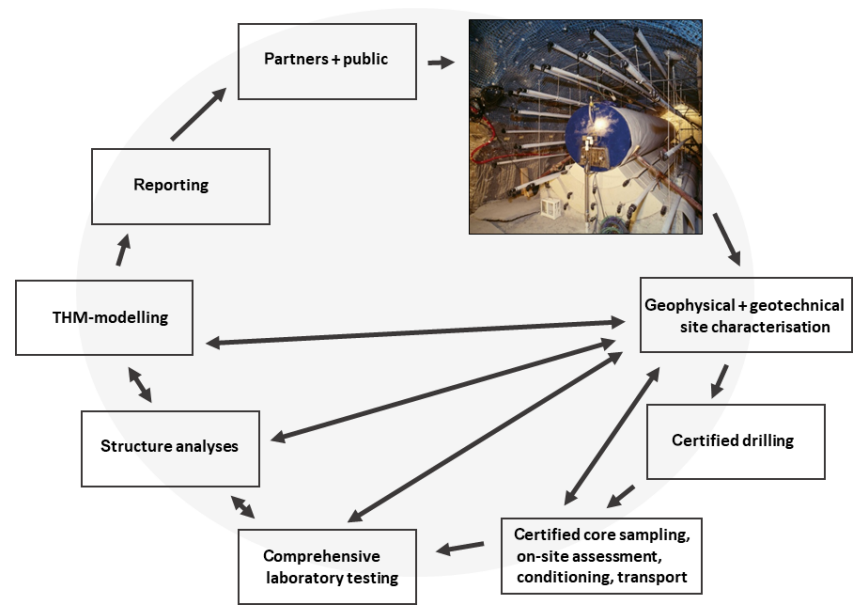

Figure 2. BGR's involvement and contributions to the complete chain of experiments supporting the Mont Terri rock laboratory; included are the main dependencies to highlight the interconnectivity.

under an angle of $45^{\circ}$. Small-scale variations are visible in both data sets documenting apparent $v_{\mathrm{p}^{-}}$and electrical resistivity distribution. Due to a borehole collapse in the Passwang Formation within the first month after drilling, the ERT measurements could be achieved only in the Opalinus Clay. These small-scale variations seem to correlate with sedimentation cycles, however, this observation has to be investigated further. Any peak in the data series can be associated with features in the core map interpretation and, hence, can be related to physical features, e.g. variations of silt-calcite layers, which are embedded in the clay matrix (Paul Bossart, personal communication, 2019). The transition from the upper shaly facies of the Opalinus Clay into the Passwang Formation is quite pronounced. By including the $v_{\mathrm{s}}$-distribution, it can be shown that the derived apparent $E_{\mathrm{dyn}}$ increases significantly, starting from values around 6 to $7 \mathrm{GPa}$ in the upper shaly facies of the Opalinus Clay to up to $50 \mathrm{GPa}$ in the Passwang Formation.

Different countries develop different concepts of engineered barriers for their planned repositories. Here, bentonite backfill in an emplacement gallery is a potential barrier. In the frame of two dummy canister emplacement experiments at Mont Terri rock laboratory (EB and HEE, see Fig. 3), geophysical methods are applied to characterise the evolution of such backfills (bentonite and sand-bentonite mixture) and the impact on host rock over the long-term. One of these experiments, the Engineered Barrier Emplacement Experiment in Opalinus Clay (EB Experiment), demonstrated a new concept for the construction of HLW repositories in horizontal drifts, especially in over-consolidated clay formations. For the initial characterisation of the EB niche, i.e. immediately after the excavation, seismic and geoelectrical measurements were performed (Schuster, 2014b; Furche and Schuster, 2014) in boreholes as well as along profiles (June to November 2001). In order to monitor the expected changes in the Opalinus Clay and the bentonite backfill during the controlled dismantling process (October 2012 to February 2013), a geoelectrical circular profile was reactivated and employed for measurements between September 2012 and May 2013. During this time span, the electrical resistivity distribution within the emplacement section and in the surrounding rock was derived on a daily basis. Under undisturbed conditions and without the influences of dismantling, the inverted spatial resistivity distribution provides an image of the homogenisation of the bentonite material due to the artificial water saturation (see Fig. 6a). Unexpectedly, an anomalous direct correlation between electrical resistivity 


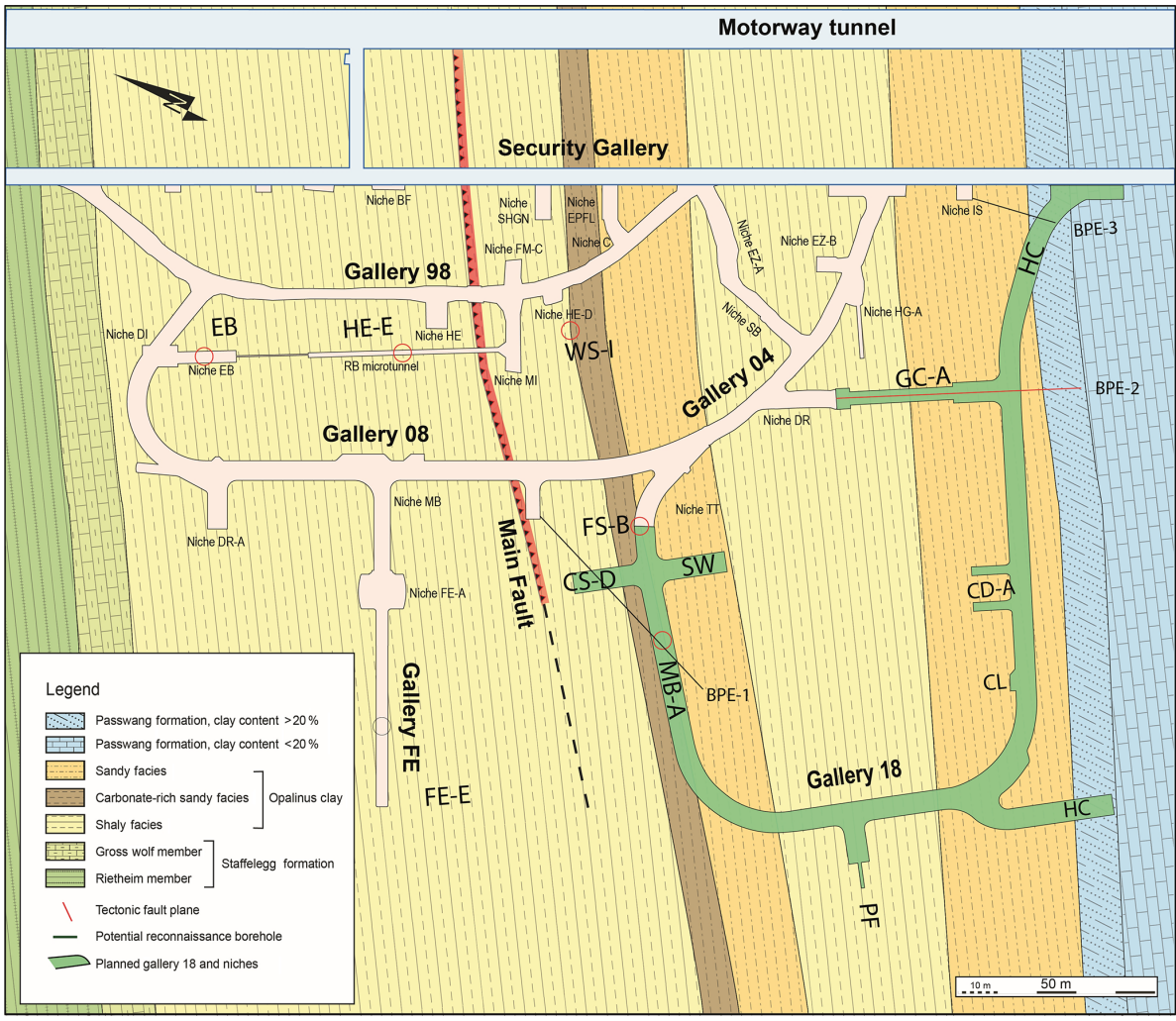

Figure 3. Map of the Mont Terri rock laboratory showing the excavation phases of the laboratory since the year 1996, recently excavated tunnels and niches are marked in green. Three exploration boreholes BPE are included as thin lines, red circles indicate experiments discussed in this paper, acronyms stand for experiments with involvement of BGR (modified after Raselli et al., 2019).

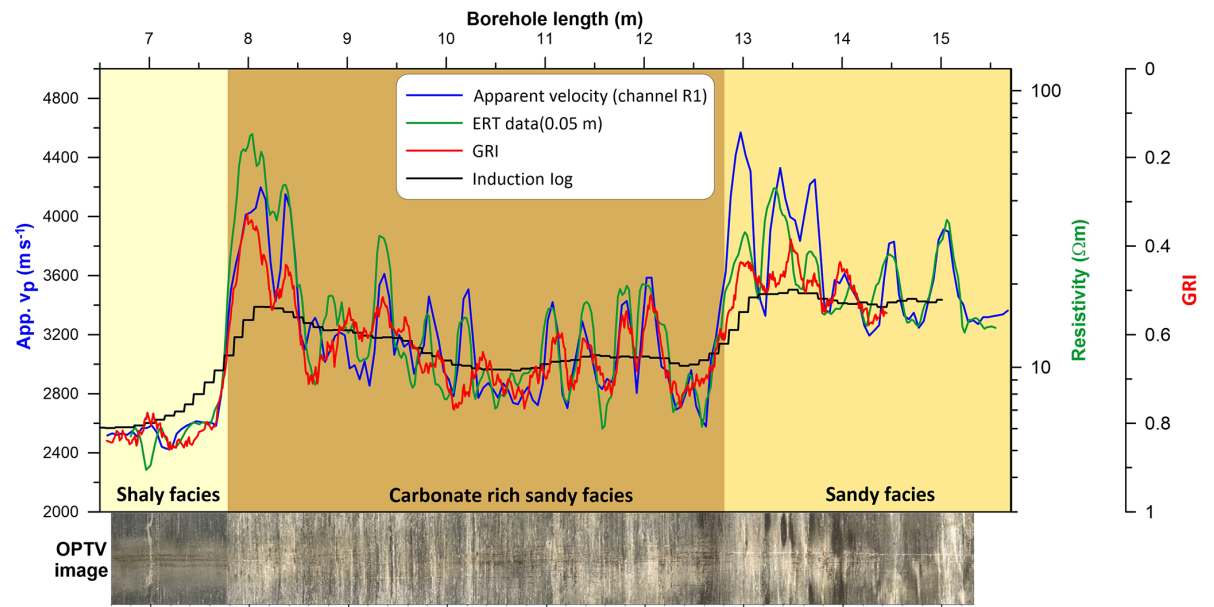

Figure 4. Comparison of geophysical and geotechnical data measured in borehole BWS-I-2, crossing the transition lower shaly, carbonaterich sandy, and sandy facies (after Furche et al., 2017).

and water content (see Fig. 6b) can be observed. The values for the water content were obtained via on-site sample analysis during the dismantling procedure. The reason for this anomalous direct correlation can be explained that in this case the clay minerals are the dominant conductors in the system and not the fluid (Kaufhold et al., 2015). Further laboratory measurements of bentonite samples confirmed this correlation.

Figure 7 shows the spatial resistivity distribution in the Opalinus Clay around the EB niche at two distinct time steps after dismantling was completed, see Fig. $6 \mathrm{a}$ and $\mathrm{b}$ : The panel on the left illustrates the spatial resistivity distribution 


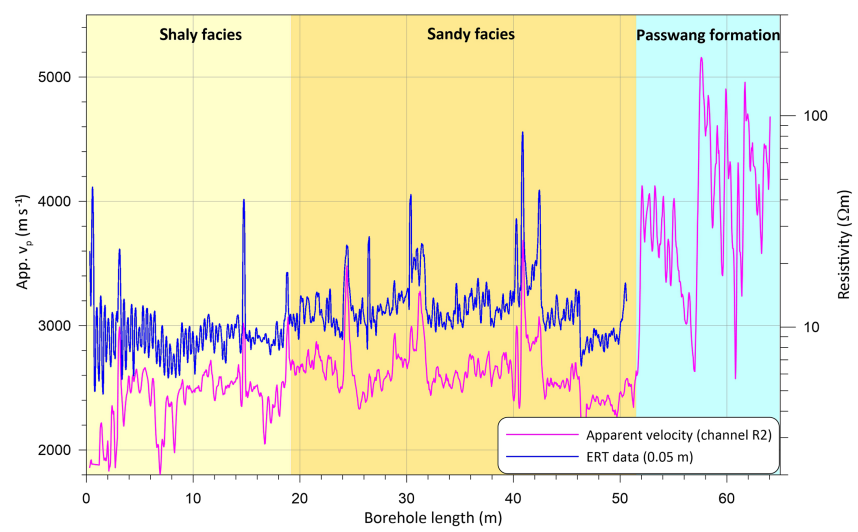

Figure 5. Results from pre-excavation explorations: Apparent velocities (channel R2) and electrical resistivity distribution measured along borehole BPE-2.

on 16 February 2013, the one on the centre, the situation on 23 May 2013. The concrete floor and the remaining concrete bed are both still visible as high resistive structures. In February, the region around the niche is characterised by resistivity values of about $10 \Omega \mathrm{m}$, except for two regions. At right top and left wall down, denoted by dashed magenta ellipses, higher resistivities $(>40 \Omega \mathrm{m})$ are visible. About three months later, these regions increase in extension as well as in their resistivity contrast. In comparison, Fig. 7c shows the spatial stress distribution as a result of a stress analysis of the EB niche before emplacement (Corkum, 2006). Obvious are two distinct broad areas of low confining stress at the left top and the bottom of the niche. Noteworthy are the two red zones, indicating areas of high deviatoric stress. These zones coincide exactly with the positions where the geoelectrical measurements show the increased resistivities. After the stress relaxation, i.e. after dismantling of the niche, this high deviatoric stress could enforce the creation of micro cracks in the Opalinus Clay. This can be seen in regions of higher resistivities in Fig. 7a and b. Hence, it can be assumed with high probability that an ongoing drying out effect intensifies the crack creation, and consequently results in higher resistivities.

The second emplacement experiment is realised with the HE-E experiment. In a $1: 2$ scale emplacement heater experiment (Gaus et al., 2014) seismic transmission measurements were performed as a long-term monitoring task (Schuster, 2014a). The installation of the instruments and the automated daily recording were carried out by a contractor (GMuG, Gesellschaft für Materialprüfung und Geophysik mbH). The aim of the seismic experiment is to characterise the evolution of the backfill material (65/35 sand/bentonite mixture) and the surrounding Opalinus Clay under thermo-hydro-mechanical (THM) in-situ conditions. Piezoelectric transmitters (four emitters and eight receivers) were installed in three boreholes, whereas one emitter and two receivers were placed in the backfill. The experiment started on 12 March 2011 (day 1) and was interrupted in 2018. Here, we discuss data from the beginning until 20 January 2015 (1411d). The first $300 \mathrm{~d}$ of the evolution in the Opalinus Clay only were discussed in detail in Bossart et al. (2019). The backfill material was emplaced between days 52 and 53 and the test section was immediately closed with a concrete plug. The heater was switched on at day 109 and the temperature of the heater elements was increased gradually until day 475 reaching $140^{\circ} \mathrm{C}$ and afterwards kept constant.

Based on the derived normalised parameter $v_{\mathrm{p}}$, the evolution of the backfill and the Opalinus Clay in the nearfield could be characterised successfully. Reliable seismic data were recorded and appropriate seismic velocities in the backfill material (Fig. 8a) from day 53 on for the ray paths at $7.5 \mathrm{~cm}$ distance from the transition of backfill to Opalinus Clay. For accuracy reasons, these measurements were performed just after the backfill material was filled in and the test section was closed by a concrete plug. In case of the $5 \mathrm{~cm}$ distance data, first reliable signals were recorded starting from day 100. Both graphs show a nearly continues parallel development, however, with significantly different gradients. Remarkable are the stagnation for $7.5 \mathrm{~cm}$ data and the weak decrease in the $5 \mathrm{~cm}$ data between days 180 and 300 . These observations are most probably due to a temporal accumulation of moisture, which was induced by a vapor front propagating from the heater towards the transition of the backfill material towards the Opalinus Clay. The increase of the normalised $v_{\mathrm{p}}$ to values of 2.9 and 3.4 implies a compaction of the backfill by $290 \%$ and $340 \%$, respectively. The notches in both graphs around days 538, 683 to 685 , and 700 result from an unwanted interruption of the heating ( $14 \mathrm{~h}$ at day 538 and $12 \mathrm{~h}$ at day 700 ) due to thunderstorms, which interrupted the power supply. The reaction of the $v_{\mathrm{p}}$-evolution is slightly delayed, first decreasing and later increasing again due to these unintended interruptions.

Figure $8 \mathrm{~b}$ depicts the $v_{\mathrm{p}}$-evolution in the Opalinus Clay for ray paths roughly $45^{\circ}$ to bedding and at four distances to the transition backfill to Opalinus Clay. The individual evolutions depend clearly on the distance to the transition. In all four of the $v_{\mathrm{p}}$ signals representing the various distances, the onset of the decrease in $v_{\mathrm{p}}$ is delayed. Also, the minima of each $v_{\mathrm{p}}$ data set is reached at different times, e.g. first for the $10 \mathrm{~cm}$ distance (green symbols) and latest for the $45 \mathrm{~cm}$ distance (black symbols). The starting values, here normalised to $v_{\mathrm{p}}$ equals one, are also reached at different times, again, the signal for the $10 \mathrm{~cm}$ distance occurs first and the one for the $45 \mathrm{~cm}$ distance last.

The very intensive ventilation could have caused the creation of an EDZ followed by a sealing $50 \mathrm{~d}$ after closing (day 100). The initial situation (normalised $v_{\mathrm{p}}=1$ ) is only reached for the $20 \mathrm{~cm}$ distance travel paths. For larger distances ( 30 and $45 \mathrm{~cm}$ ), the normalised value for $v_{\mathrm{p}}$ stays at 1.04. This result implies a slightly higher consolidation of the Opalinus Clay compared to the initial situation. Surprising 

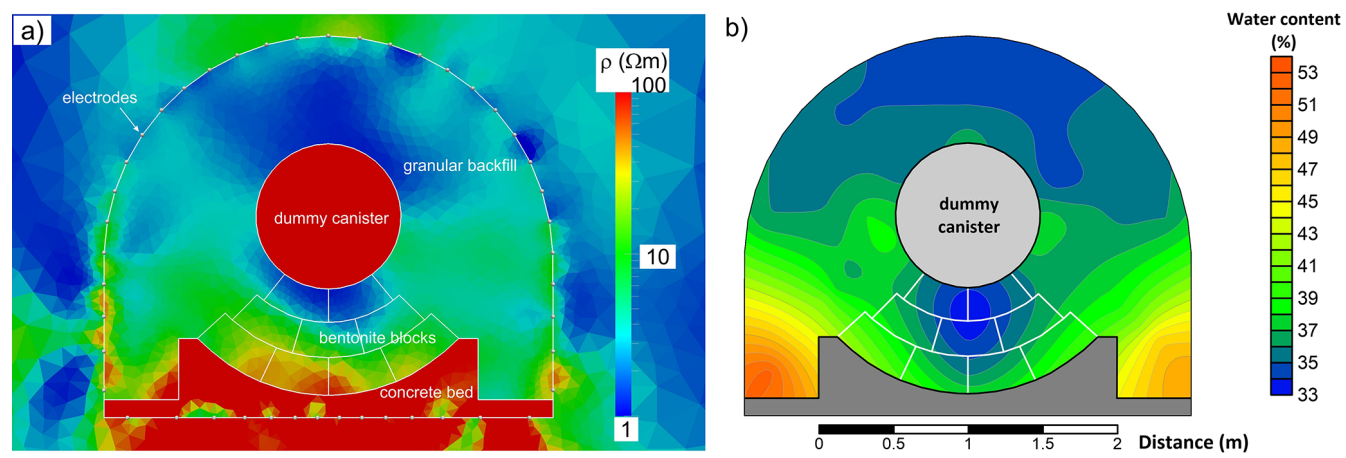

Figure 6. (a) Model of the spatial resistivity distribution on 30 September 2012 (Furche and Schuster, 2014); (b) spatial distribution of water content as a result of sample analysis while dismantling (after Palacios et al., 2013).
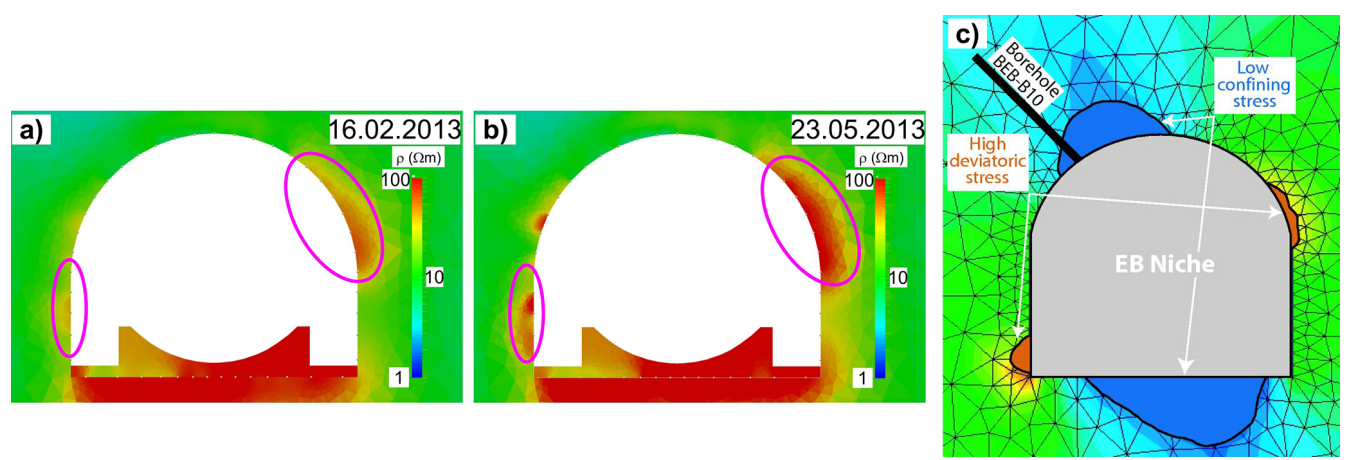

Figure 7. (a, b) Resistivity distribution in the Opalinus Clay around the EB niche at two distinct time steps after finishing the dismantling (after Furche and Schuster, 2014) 16 February and 23 May 2013; (c) spatial stress distribution in the environment of the EB niche (after Corkum, 2006).

is the drop of $v_{\mathrm{p}}$ at $10 \mathrm{~cm}$ after $400 \mathrm{~d}$. It could be caused by an accumulation of moisture in this region. A lower frequency content of the signals supports this interpretation. The moisture could originate either (i) from the backfill material as a heat driven vapor front or (ii) from the Opalinus Clay itself due to stress redistribution, so-called "wet spot like".

\subsection{Hydraulic characterisation}

Another focus of the BGR research programme lies on hydraulic characterisation. This includes permeability measurements, which were performed in the near-field around an excavation, in the undisturbed rock zone, in the zone with wet-spots, and in the transition area between different geological units. To determine the permeability of a rock, a hydraulic or pneumatic packer test in a predrilled borehole is still the mostly used in-situ method. This procedure is not a non-destructive one, because the drilling of the borehole disturbs the initial rock state and may also induce changes in the rock properties in the vicinity of a borehole (so-called Bd/DZ: borehole disturbed/damaged Zone), see Schuster et al. (2017).
Successful measurements have been performed to characterise hydraulic properties in the near-field. A typical distribution of the permeability along boreholes around a tunnel is documented in Fig. 9, left panel. The measurements were carried out via injection of nitrogen, about one year after the tunnel excavation. The location in the deep tunnel section had no shotcrete support. It is obvious that in the clay matrix zone from $2.5 \mathrm{~m}$, the measured permeability to gas is lower than the initial permeability of $1 \times 10^{-20} \mathrm{~m}^{2}$ due to the high gas entry pressure. Up to a $2.5 \mathrm{~m}$ distance to the tunnel wall, a significant increase in permeability was detected. This change was caused on the one hand by stress redistribution. In the case without shotcrete, the convergence rate is higher than with shotcrete. The consequences are the generation of micro cracks and damage around the opening. On the other hand, the ventilation leads to a reduction of moisture in the near-field via micro and macro cracks. Without shotcrete, the tunnel surface has direct contact with the ventilated air. As the reduction of the water saturation is associated with a shrinkage of the clay rock, the permeability increases further. Therefore, when shotcrete is used as a support system for the construction of a repository for radioactive waste or for tunnelling in claystone, it has to be used directly after the excavation. The advantage in this instance is that the 

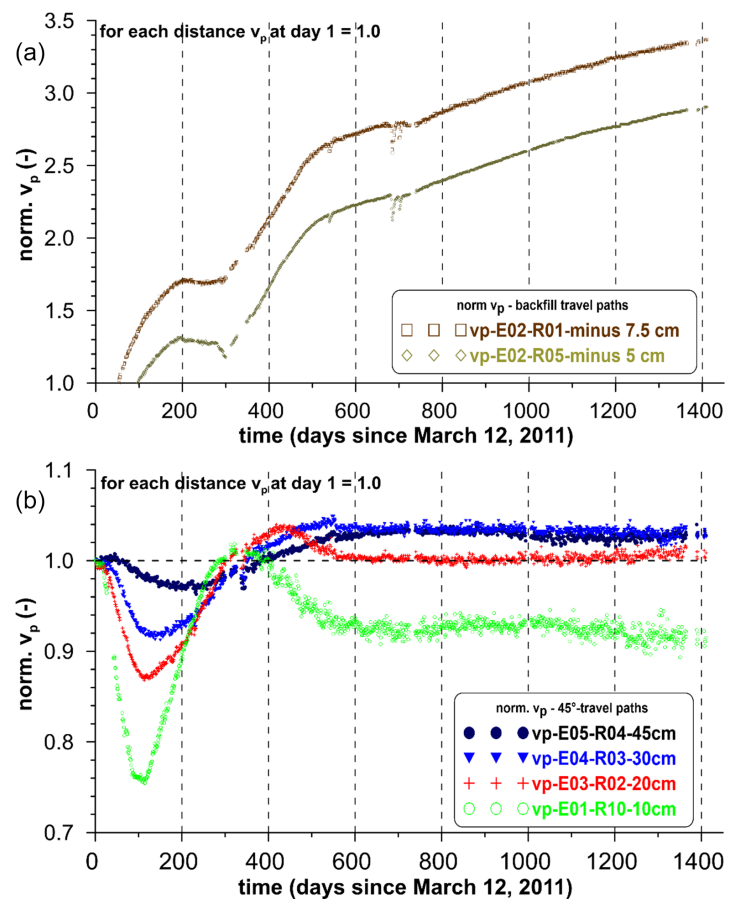

Figure 8. Seismic transmission long-term monitoring within the HE-E experiment via normalised $v_{\mathrm{p}}$-evolution. (a) In the back fill (sand-bentonite) at distances of 7.5 and $5 \mathrm{~cm}$ from the transition; (b) in the Opalinus Clay at four distances from the transition and ray paths running under $45^{\circ}$ towards the bedding (after Schuster, 2018).

extension of a zone with an increase in permeability reaches only about $1.5 \mathrm{~m}$ away from the tunnel wall (Shao et al., 2017a). In fact, the fracture network in the EDZ will seal in time due to swelling processes of the fracture surfaces, and thus reduce the permeability (Bossart et al., 2002; Zhang, 2011).

In order to understand these strongly coupled thermalhydro-mechanical (THM) processes, the numerical code OpenGeoSys (OGS) was developed in cooperation with the Centre for Environmental Research UFZ Leipzig (Kolditz et al., 2012). Among a broad variety of applications, OGS is being widely used to analyse the complicated HM and THM coupled processes occurring in several largescale experiments at Mont Terri rock laboratory, e.g. the Mine-by test in the sandy facies (MB-A) and the Full scale Emplacement experiment (FE), a 1:1 heater test. Within the framework of the FE-M project (Monitoring and Modelling), a numerical modelling of the heating phase was conducted. In the present 3-D model, an EDZ with a permeability of $1 \times 10^{-19}$ to $5 \times 10^{-20} \mathrm{~m}^{2}$ as reference value is clearly underestimated. While a good agreement between numerical and measured results (temperature and pore water pressure) in the far field in the rock is achieved, a significant discrepancy of the pore pressure in the nearfield (BFEA002 TEM/PRE 03) is observed, compare Fig. 9 b.
In order to better understand the measured permeability, the distribution can serve as a complement to the database for further modelling of the ongoing THM monitoring.

\subsection{Mine-by experiment}

In former years, most of the investigations in the Mont Terri rock laboratory have been implemented in the shaly facies of the Opalinus Clay. Yet, with the extension of the Mont Terri rock laboratory, most of the new Gallery 18 will be excavated in the more stable sandy facies of the Opalinus Clay, refer Fig. 3. This provides the opportunity to investigate hydraulic and mechanical behaviour of this stratigraphic unit and to compare the results with the ones obtained for the shaly facies. The aim of the Mine-by Experiment (MB-A) is to capture coupled hydromechanical processes induced by the excavation. The measured results will be the basis of computational simulations to determine the property values of the sandy facies. Therefore, in advance of the excavation, a section of the planned gallery has been instrumented with different sensors to measure deformation, stress changes, and changes of pore pressure. Drilling and instrumentation were carried out in an almost undisturbed rock mass more than six months prior to the excavating of this gallery section. The reason behind the early installation was to reach a new state of equilibrium in the rock mass after the disturbance due to the drilling and instrumentation work. The vertical deformation has been observed with inclinometers located above and below the future gallery. Horizontal deformation has been measured with extensometers in the gallery axis as well as parallel to the drift wall. In addition, two extensometers cross the future gallery. With this geometry, the central parts of the extensometers will be excavated. The development of pore pressure has been observed with several piezometers in and around the future gallery, with a reference measurement in a distance of $15 \mathrm{~m}$ to the drift. Close to the piezometers around the gallery, stress monitoring systems have been placed to record the changes of stresses and to determine effective stresses in the rock mass. A sketch of the investigation area and the instrumentation is given in Fig. 10.

In addition to the continuous monitoring, repeated measurements in two boreholes parallel to the drift will be conducted using MSM and ERT. With these geophysical methods, the development of the excavation damaged zone (EDZ) in the contour of the gallery will be observed as well as the saturation in the nearfield of the gallery. At this moment, it is too early to present measuring results, because the excavation is taking place in May 2019, just as we were preparing this paper. So far, all sensors and instruments are working well. Until now, the measured data show very good results and clearly display the influence of the excavation process on the observed processes. 

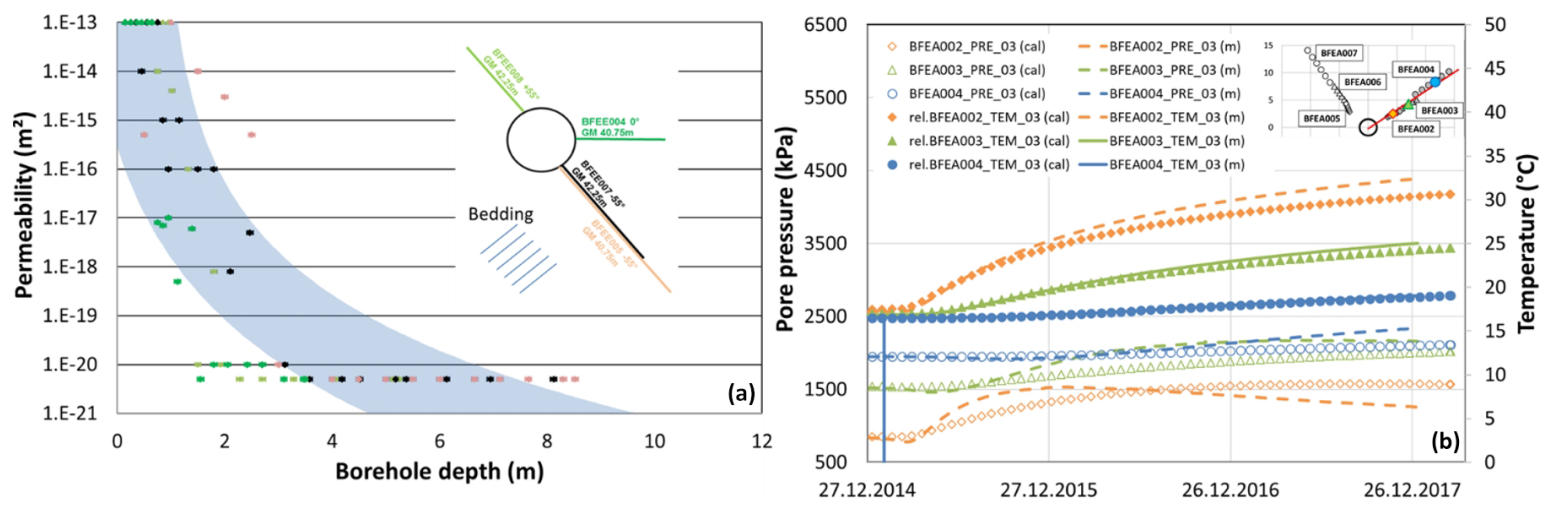

Figure 9. Permeability distribution around the FE-tunnel in the section without shotcrete (a, after Shao et al., 2017a) and comparison between measured and modelled temperature and pore water pressure in the boreholes during the heating phase (b).
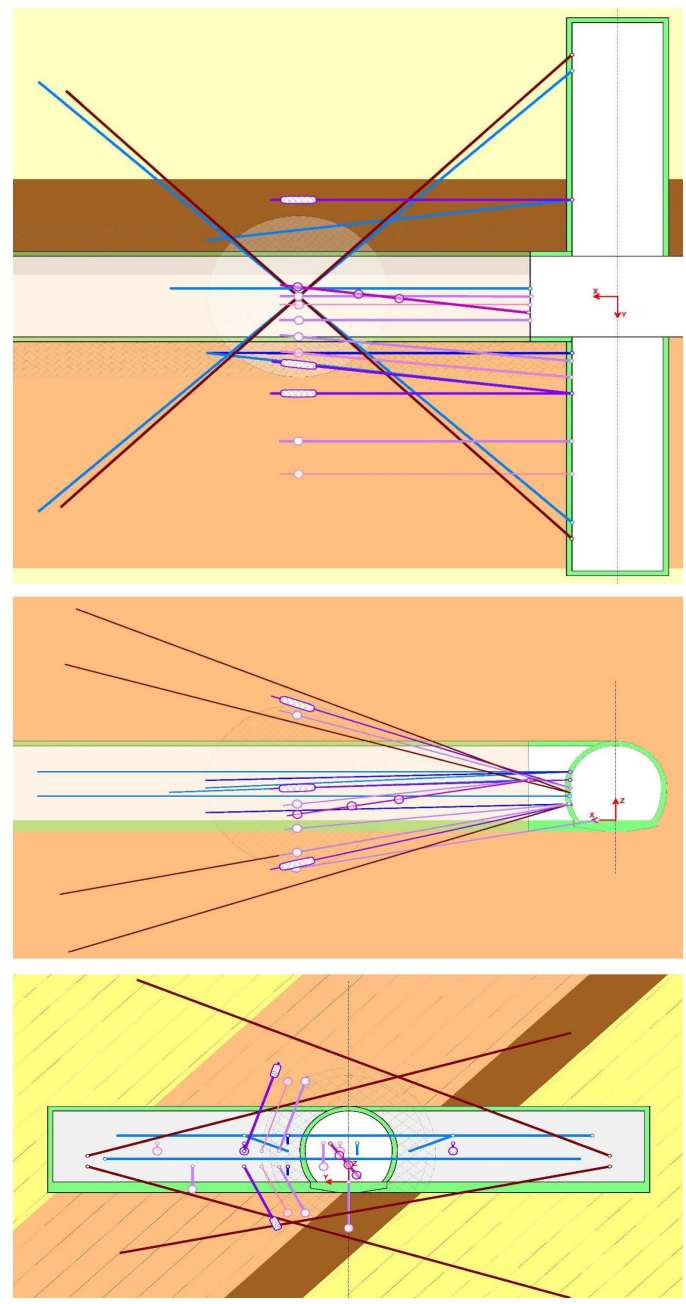

Figure 10. Location of the Mine-by Experiment MB-A and its instrumentation; brown lines, inclinometers for vertical deformation; blue lines, extensometers for horizontal deformation; pink lines, piezometers for pore pressure; purple lines, stress monitoring systems for stress changes.

\subsection{Laboratory tests}

Since Opalinus Clay is an anisotropic material, it is to be expected that its mechanical parameters depend on the orientation of the material relative to the mechanical loading. Furthermore, observations on other types of porous rocks (Mogi, 1965; Kulhawy, 1975; Verman et al., 1997; Li et al., 1999; Asef and Najibi, 2013) suggest that the mechanical properties depend on the confining pressure. As a first step towards the study of these dependencies in the case of Opalinus Clay, we performed drained triaxial tests in Kármán cells. Cylindrical claystone samples from the sandy facies of Mont Terri originating from boreholes with different orientations relative to the bedding were subjected to a series of loading-unloading cycles. While doing this, the confining pressure was changed from one cycle to the next (exemplarily, see Fig. 11). In order to avoid damaging the material during these tests, the axial pressure was restricted to one-third of the lowest compressive strength measured for the respective orientation. Subsequently, the elastic moduli were calculated based on the stress-strain data and plotted against the confining pressures.

The Young's modulus was found to exhibit a significant dependency on the confining pressure, in that it increases monotonously with the latter. This can be explained in a general fashion by an increase of the internal friction due to the radial loading. It is noteworthy that not only the values of the parameters depend on the orientation of the sample relative to the bedding, but furthermore, the type of the functional dependency of the elastic modulus on the confining pressure changes with the orientation. In more detail, the dependency of the elastic modulus on the confining pressure can be described by power laws with material-dependent coefficients.

In particular, samples drilled perpendicular or at an oblique angle to the bedding plane show a linear dependence, refer Figs. 12 and 13:

$E=E_{0}+a \sigma_{3}$ 


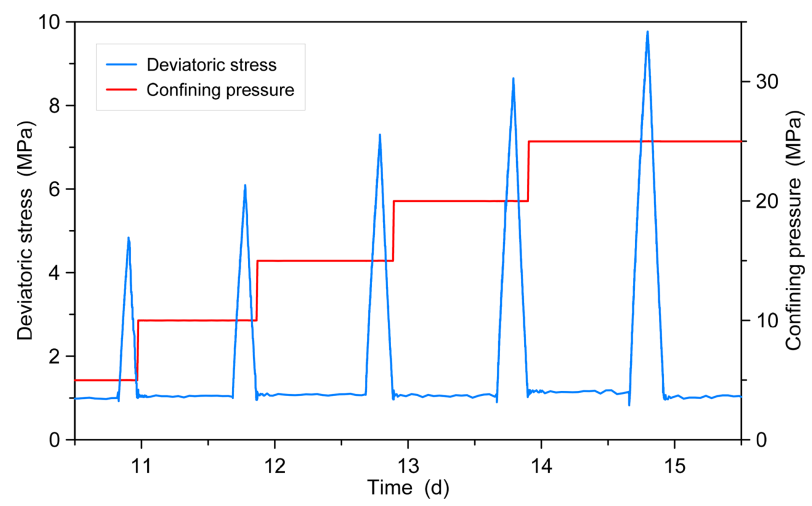

Figure 11. Stepwise changes of the confining pressure (red) and loading-unloading cycles shown through changes in the effective pressure (blue).

Whereas for samples drilled parallel to the bedding plane, a power law fits the data best, see Fig. 14:

$E=c\left(\frac{\sigma_{3}}{1 \mathrm{MPa}}\right)^{b}$.

Here, the parameters $a$ and $b$ are dimensionless, $c$ has the unit MPa.

Table 1 presents the values of the parameters for some samples of different orientation and location. Taking into account (i) the natural variability of the Opalinus Clay, (ii) the facts that only a limited number of samples could be examined, and (iii) that the sampling locations were situated at considerable distances from each other, the parameters obtained for the individual samples may not be considered yet as representative for the whole facies, much less for Opalinus Clay in general. However, they already give an indication of the order of magnitude and the types of functional dependencies to be expected, and may thus already be useful for the development of numerical models studying the mechanical behaviour.

Although the circumstances of the sample extraction and the experimental setup have only allowed for the examination of one orientation per sample, the results indicate that a higher elastic modulus is to be expected parallel to the bedding rather than perpendicular to it. This ties in with observations on other rocks of similar, approximately transversally isotropic structure, and is explained with a preferred orientation of the constituent minerals parallel to the bedding and the presence of a higher cross-section of materials with a low rigidity perpendicular to it (Lo et al., 1986).

One possible explanation for the different types of the functional dependency of Young's modulus on the confining pressure could be provided by the effect of the oblong pores in the material whose greater axes are oriented mostly parallel to the bedding plane (Kanitpanyacharoen et al., 2015). If the confining pressure is applied parallel to the bedding plane as is the case for the sample from borehole
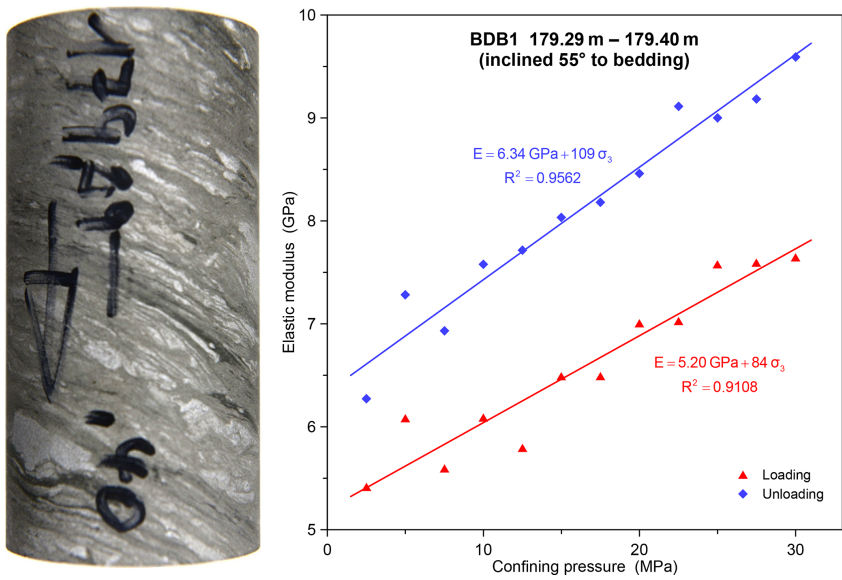

Figure 12. Sample from BDB-1 borehole (drill depth from 179.29 to $197.40 \mathrm{~m}$ ) and dependency of elastic modulus on confining pressure.
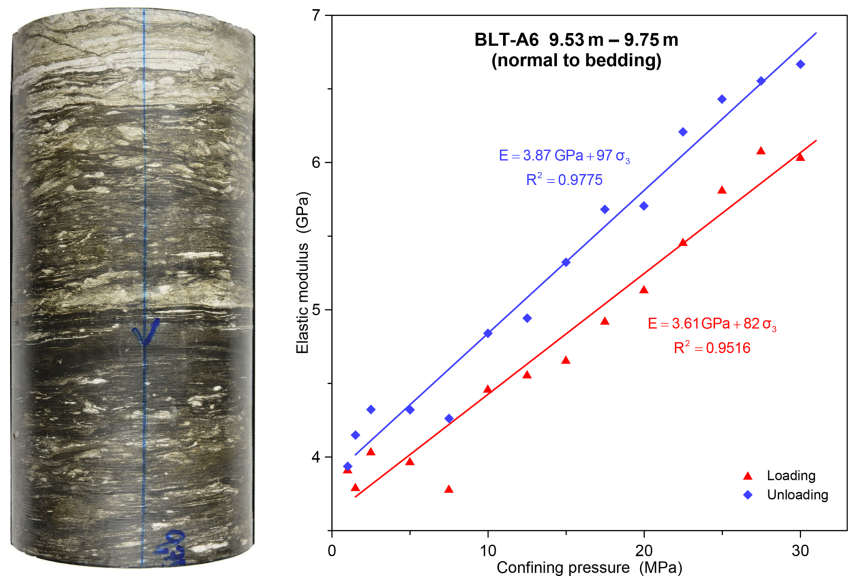

Figure 13. Sample from BLT-A6 borehole (drill depth from 9.53 to $9.75 \mathrm{~m}$ ) and dependency of elastic modulus on confining pressure.

BLT-A6, these pores are kept open and present a significant low-rigidity material component to the axial compression. While for the orientation of the samples from borehole BLT$\mathrm{A} 8$, the pores tend to be closed by the confining pressure. With increasing pressure, the material behaves more and more like a compact one, such that the dependency of the elastic modulus on the confining pressure becomes weaker with the increase of the latter. This argumentation can be supported mathematically by an application of the method of Eshelby (1957) on ellipsoidal pores (David and Zimmerman, 2011).

Obviously, the supporting effects of the confining pressure on the pores still prevail in the sample from borehole BDB1 , which has been drilled at an angle of about $55^{\circ}$ to the bedding plane. It is to be expected that the transition between the two types of functional dependency will occur at an even shallower angle between bedding and drill 
Table 1. Parameters of the dependence of the elastic modulus on the confining pressure for Opalinus Clay samples from Mont Terri rock laboratory.

\begin{tabular}{|c|c|c|c|c|c|c|}
\hline \multirow[t]{3}{*}{ Borehole } & \multirow[t]{3}{*}{ Drill depth (m) } & \multirow{3}{*}{$\begin{array}{l}\text { Angle of } \\
\text { drilling } \\
\text { axis to } \\
\text { bedding }\end{array}$} & \multicolumn{4}{|c|}{$E=E_{0}+a \sigma_{3}$} \\
\hline & & & \multicolumn{2}{|c|}{ Load increasing } & \multicolumn{2}{|c|}{ Load decreasing } \\
\hline & & & $E_{0}(\mathrm{MPa})$ & $a$ & $E_{0}(\mathrm{MPa})$ & $a$ \\
\hline BDB-1 & 179.29 to 179.40 & $55^{\circ}$ & $5200 \pm 160$ & $84 \pm 9$ & $6340 \pm 140$ & $109 \pm 8$ \\
\hline BLT-A6 & 9.53 to 9.75 & $90^{\circ}$ & $3610 \pm 100$ & $82 \pm 6$ & $3870 \pm 80$ & $97 \pm 4$ \\
\hline \multirow[t]{3}{*}{ Borehole } & \multirow[t]{3}{*}{ Drill depth (m) } & \multirow{3}{*}{$\begin{array}{l}\text { Angle of } \\
\text { drilling } \\
\text { axis to } \\
\text { bedding }\end{array}$} & \multicolumn{4}{|c|}{$E=c\left(\frac{\sigma_{3}}{1 \mathrm{MPa}}\right)^{b}$} \\
\hline & & & \multicolumn{2}{|c|}{ Load increasing } & \multicolumn{2}{|c|}{ Load decreasing } \\
\hline & & & $c(\mathrm{MPa})$ & $b$ & $c(\mathrm{MPa})$ & $b$ \\
\hline BLT-A8 & 9.70 to 9.92 & $0^{\circ}$ & $9470 \pm 140$ & $0.201 \pm 0.005$ & $11030 \pm 160$ & $0.173 \pm 0.006$ \\
\hline BLT-A8 & 9.45 to 9.67 & $0^{\circ}$ & $11790 \pm 90$ & $0.162 \pm 0.003$ & $12920 \pm 70$ & $0.145 \pm 0.002$ \\
\hline
\end{tabular}
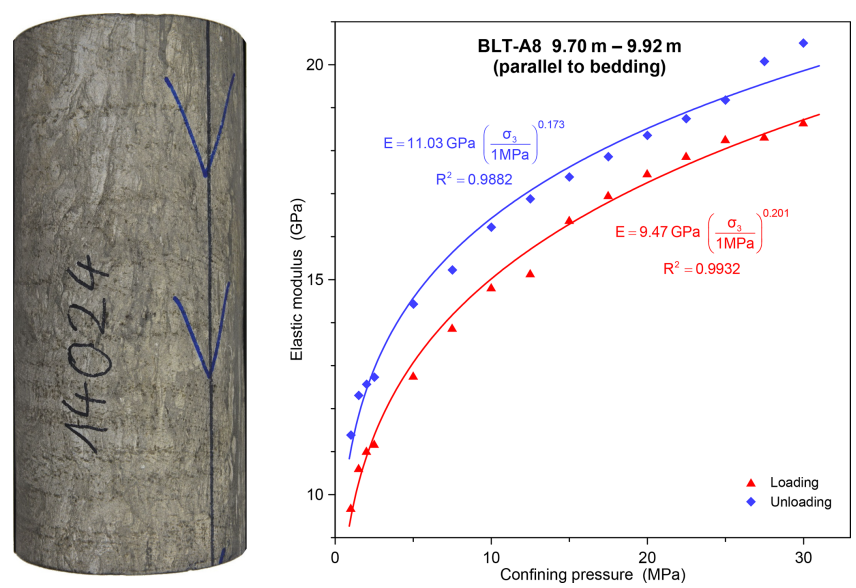

Figure 14. Sample from BLT-A8 borehole (9.70 to $9.92 \mathrm{~m})$ and dependency of elastic modulus on confining pressure.

direction. We emphasise that, in addition to the Young's moduli parallel and perpendicular to the bedding, three more elastic parameters are needed for a complete description of the behaviour of an approximately transversally isotropic material such as Opalinus Clay. The complete parameter set, however, cannot easily be determined in Kármán cells, as a reliable determination of the radial or circumferential deformation of the samples is difficult to achieve. For this purpose, true triaxial tests will be necessary. With these, we also expect to be able to compare the static with the dynamic elastic parameters. The latter will allow a more direct comparison with data obtained from microacoustic insitu measurements.

\section{Discussion and conclusion}

All presented techniques and results aim at contributing to special aspects of understanding the evolution and behaviour of underground facilities during all operation phases. Results are used internally and between experiment partners for a mutual enhancement of scientific understanding and comprehensive interpretation of geomechanical aspects. For example, results from EDZ-characterisation achieved with hydraulic and pneumatic methods (Sect. 2.2) correlate very well with findings from Mini-Seismic Methods (MSM, Sect. 2.1) at the same locations (Shao et al., 2017b). The same is valid for the comparison of static elastic moduli found in laboratory tests (Sect. 2.4) and dynamic elastic moduli measured in-situ with MSM (Sect. 2.1). The discrepancy between both is a well-known problem. In several experiments in the Mont Terri rock laboratory, a factor of 2.5 was found, describing the relation between static and dynamic elastic moduli, e.g. Young's modulus $E_{\mathrm{dyn}} \approx$ $2.5 \times E_{\text {stat }}$ (Schuster et al., 2017). Significant efforts are currently under way to establish a more quantitative relation between both domains, what the authors call a reconciliation of both domains (Giger et al., 2018). Such relationships would allow the assessment of elastic in-situ behaviour of any rock mass by applying borehole based seismic methods. Derived seismic parameters from MSM are generally used for geomechanical relevant local site characterisations. For example, the derived small-scale variations of seismic Pwave velocities, derived in borehole BWS-I-2 (Fig. 4), were used to calculate dynamic elastic moduli. Because very similar results were found in several other boreholes, crossing the same facies types of the Opalinus Clay under same orientations towards the bedding, these results are used to support the modelling of data achieved in the MB-A experiment (Sect. 2.3). In such cases, results are projected to an appropriate location in the MB-A tunnel. Furthermore, the derived small-scale variability in measured seismic and geoelectrical parameters, which reflect directly the dynamic elastic moduli, has to be considered in geomechanical models. Distributions of derived seismic and geoelectric parameters at several locations in the Mont Terri 
rock laboratory show typical patterns. This can be seen as a characteristic "fingerprint" of the Opalinus Clay.

All investigations were performed during the last 20 years in the Opalinus Clay of the Mont Terri rock laboratory. However, only some selected ones could be presented exemplarily in this paper. Here, the emphasis lies on the three facies types, the anisotropy of geophysical and geotechnical parameters, the small-scale variability (sedimentation cycles), the small-scale heterogeneities, and the existing fractures and disturbances due to excavations. All of them have to be taken into account for a comprehensive understanding of all processes in an underground facility, especially in a final repository. Furthermore, temporal variations and changes of rock properties, depending on the excavation and backfilling (Ed/DZ, Bd/DZ) were recorded and have to be taken into consideration for different construction phases of any final repository. Furthermore, Opalinus Clay is of special interest due to its properties that are representative of a caprock, a crucial constituent for numerous potential uses of the subsurface. With the recent excavation of Gallery 18, the Mont Terri rock laboratory provides now access to undisturbed rock regions once more. This offers the opportunity to open the unique conditions and state-of-the-art facility to new, different scientific user groups. Novel experiments are planned investigating further areas of social relevance, related e.g. to carbon sequestration and geothermal energy projects. We anticipate that the exchange of ideas, approaches, techniques, and instrumentations will be of great mutual benefit to the different scientific communities involved.

With our method developments, BGR aims to provide robust and practical tools with a reasonable spatial resolution for in-situ derived geophysical and geotechnical parameters. All aspects presented here were discussed for claystone, but can, and in fact some already are, applied in other potential host rocks for nuclear waste as well. The comprehensive tools, exemplarily documented here, allow for needed tailored solutions of fast and reliable site assessment of potential nuclear waste repositories. However, the obtained technical and scientific gain can be effectively adapted and employed in other subsurface uses as well. Despite the enormous efforts of all partners involved and the vast, often times interdisciplinary knowledge that has been acquired, important answers to various technical and scientific questions have yet to be found. Finally, we would like to stress that all developments and experiences, which are made in the excellently equipped international Mont Terri rock laboratory will be used in the German site selection program, regardless of the host rock chosen for a final HLW repository in Germany.

Data availability. All data are measured by the authors and their technical staff with very specific formats. They are documented and described in the cited publications, and are available on request following the regulation of the Mont Terri Consortium.

Author contributions. All authors designed their experiments, which are presented in the appropriate chapters, performed measurements with the help of their technical staff, evaluated and interpreted the data (KS and MF: Sect. 2.1, HS: Sect. 2.2, JH: Sect. 2.3, JMH and WG: Sect. 2.4). DR works actually on CCS and geothermal experiments recently incorporated in the Mont Terri Project. In addition, all authors wrote text passages, provided figures, and were involved in editing the paper.

Competing interests. The authors declare that they have no conflict of interest.

Special issue statement. This article is part of the special issue "European Geosciences Union General Assembly 2019, EGU Division Energy, Resources \& Environment (ERE)". It is a result of the EGU General Assembly 2019, Vienna, Austria, 7-12 April 2019 .

Acknowledgements. All in-situ and laboratory experiments were facilitated by a huge number of BGR technicians and engineers. Many thanks for the engagement to (in alphabetical order): Hendrik Albers, Dieter Boeddener, Sarina Börner, Uwe Brockmann, Christoph Czora, Gerd Dettmer, Peter Eichhorn, Adrian Engelke, Clemens Fixar, Jana Gerowski, Hendrik Heinemann, Sebastian Klösters, Ulf Nowak, Daniel Nowotny, Benjamin Paul, Silvio Sanchez-Herrero, Friedhelm Schulte, Wilfried Stille, and Torsten Tietz. In addition, the authors would like to thank all members of the Mont Terri consortium for their constant and ongoing cooperation, numerous open discussions, and the fruitful and friendly atmosphere. Funding for BGR's investigations were provided by the German Bundesministerium für Wirtschaft und Energie. We also thank both reviewers, who provided many very helpful suggestions and comments, hence, improving structure and readability of the paper.

Review statement. This paper was edited by Thomas Nagel and reviewed by Paul Bossart and one anonymous referee.

\section{References}

Asef, M. R. and Najibi, A. R.: The effect of confining pressure on elastic wave velocities and dynamic o static Young's modulus ratio, Geophysics, 78, D135-D142, 2013.

Bossart, P., Meier, P. M., Moeri, A., Trick, T., and Mayor, J. C.: Geological and hydraulic characterization of the excavation disturbed zone in the Opalinus Clay of the Mont Terri Rock Laboratory, Eng. Geol., 66, 19-38, 2002.

Bossart, P., Bernier, F., Birkholzer, J., Bruggeman, J., Connolli, P., Dewonck, S., Fukaya, M., Herfort, Jensen, M., Matray, J.-M., 
Mayor, J. C., Moeri, A., Oyama, T., Schuster, K., Shigeta, N., Vietor, T., and Wieczorek, K.: Mont Terri rock laboratory, 20 years of research: introduction, site characteristics and overview of experiments, in: Mont Terri rock laboratory, 20 years, 3-22, https://doi.org/10.1007/s00015-016-0236-1, Birkhäuser, Cham, 2018.

Bossart, P., Nussbaum, C., and Schuster, K.: Generation and Self-Sealing of the Excavation-Damaged Zone (EDZ) around a Subsurface Excavation in a Claystone, Shale, 125-143, https://doi.org/10.1002/9781119066699.ch8, 2019.

Corkum, A. G.: Non-linear behaviour of Opalinus Clay around underground excavations, PhD thesis, Department of Civil and Environmental Engineering, University of Alberta, Canada, 2006.

David, E. C. and Zimmerman, R. W.: Compressibility and shear compliance of spheroidal pores: Exact derivation via the Eshelby tensor, and asymptotic expressions in limiting cases, Int. J. Solids Struct., 48, 680-686, 2011.

Eshelby, J. D.: The determination of the elastic field of an ellipsoidal inclusion, and related problems, Proc. R. Soc. Lond. A-Mat., 241, 376-396, 1957.

Furche, M. and Schuster, K.: EB-Experiment - Geoelectrical monitoring of dismantling operation, available at: https:// www.pebs-eu.de/PEBS/EN/Downloads/D2_19.pdf (last access: 25 October 2019), 2014.

Furche, M., Schuster, K., and Meima, J.: Geophysical characterisation of different lithofacies and correlations with other Opalinus Clay parameters Mont Terri rock laboratory, 7th International Conference on "Clays in Natural and Engineered Barriers for Radioactive Waste Confinement”, Nagra, Wettingen, Switzerland, 2017.

Gaus, I., Wieczorek, K., Schuster, K., Garitte, B., Senger, R., Vasconcelos, R., and Mayor, J.-C.: EBS behaviour immediately after repository closure in a clay host rock: HE-E experiment (Mont Terri URL), Geol. Soc. Lond. Spec. Publ., 19, 71-91, https://doi.org/10.1144/SP400.11, 2014.

Giger, S. B., Lozovyi, S., Bauer, A., Schuster, K., Furche, M., and Martin, D.: Reconciling static and dynamic elastic properties of Opalinus Clay at multiple scales, in: SEG proceedings, Lausanne, 2018, Extended abstract, Google Scholar, available at: https://seg2018.epfl.ch/wp-content/uploads/2018/ 08/EA_175_Giger.pdf (last access: 30 October 2019), 2018.

Kanitpanyacharoen, W., Vasin, R., Wenk, H. R., and Dewhurst, D. N.: Linking preferred orientations to elastic anisotropy in Muderong Shale. Australia, Geophysics, 80, C9-C19, 2015.

Kaufhold, S., Dohrmann, R., Klinkenberg, M., and Noell, U.: Electrical conductivity of bentonites, Appl. Clay Sci., 114, 375$385,2015$.

Kolditz, O., Shao, H., Görke, U.-J., and Wang, W.: Thermohydro-mechanical-chemical processes in fractured porous media - Benchmarks and examples, Vol. 86, Lecture Notes in Computational Science and Engineering, Springer, ISBN 9783-642-27177-9, 2012.

Kulhawy, F. H.: Stress deformation properties of rock and rock discontinuities, Eng. Geol., 9, 327-350, 1975.

Li, H. B., Zhao, J., and Li, T. J.: Triaxial compression tests on a granite at different strain rates and confining pressures, Int. J. Rock Mech. Min., 36, 1057-1063, 1999.
Lo, T.-W., Coyner, K. B., and Toksöz, M. N.: Experimental determination of elastic anisotropy of Berea sandstone, Chicopee shale, and Chelmsford Granite, Geophysics, 51, 164-171, 1986.

Mogi, K.: Deformation and Fracture of Rocks under Confining Pressure (2): Elasticity and Plasticity of Some Rocks, B. Earthq. Res. I., 43, 349-379, 1965.

Palacios, B., Rey, M., Garcia-Sinerez, J. L., Villar, M. V., Mayor, C., and Velasco, M.: Engineered Barrier Emplacement Experiment in Opalinus Clay "EB" Experiment. As-built of dismantling operation, PEBS Deliverable D2.1-4, 188 pp., 2013.

Raselli, R., Galletti, M., Jaeggi, D., Schefer, S., Nussbaum, C., and Bossart, P.: Gallery 2018: Excavation and geological documentation, swisstopo Technical Note 2018-80, November 2019, Switzerland, in preparation, 2019.

Schuster, K.: Seismic data report on EDZ and EBS evolution (HEE). PEBS Deliverable D2.2-10, available at: http://www.pebs-eu. de/PEBS/EN/Downloads/downloads_node_en.html (last access: 25 October 2019), 2014a.

Schuster, K.: EDZ seismic results - seismic transmission measurements. PEBS Deliverable D2.1-6, available at: https://www.pebs-eu.de/PEBS/EN/Downloads/D2_1_6.pdf; jsessionid=5E5006F81677F97F1D78991428424715.1_cid321? _blob=publicationFile \&v=1 (last access: 28 October 2019), 2014b.

Schuster, K.: HE-E Experiment: Seismic long-term measurements: Interim report with exemplary quantitative and qualitative results until November 2017, swisstopo, Technical Note TN 2016-79, Wabern, Switzerland, 2018.

Schuster, K.: Mini-Seismic Methods for the in-situ characterization of clay rocks - Examples from URL Meuse/Haute-Marne (France) and HADES URF (Belgium), Geomechanics for Energy and the Environment, 17, 16-28, https://doi.org/10.1016/j.gete.2018.09.005, 2019.

Schuster, K. and Furche, M.: WS-I experiment: High resolution geophysical measurements in borehole BBB3, Mont Terri. Technical Note, TN 2013-75, swisstopo, Wabern, Switzerland, 2016.

Schuster, K., Amann, F., Yong, S., Bossart, P., and Connolly, P.: High-resolution mini-seismic methods applied in the Mont Terri rock laboratory (Switzerland), Swiss J. Geosci., 110, 213-231, https://doi.org/10.1007/s00015-016-0241-4, 2017.

Shao, H., Paul, B., Wang, X., Hesser, J., Becker, J., Garitte B., and Müller, H.: The influence of different supports on the properties of the excavation damaged zone along the FE tunnel in the Mont Terri Underground Rock Laboratory, Geol. Soc. Spec. Publ., 443, 149-157, 2017a.

Shao, H., Göthling, S., Liu, W., Hesser, J., Morel J., and Sönnke, J.: Quantitative characterization of the excavation damaged zone fracture network in the Meuse/Haute-Marne Underground Research Laboratory: in situ experiment and numerical interpretation of helium injection test, Geol. Soc. Spec. Publ., 443, 85-96, 2017b.

swisstopo: available at: https://www.mont-terri.ch, last access: 7 September 2019.

Verman, M., Singh, B., Viladkar, M. N., and Jethwa, J. L.: Effect of tunnel depth on modulus of deformation of rock mass, Rock Mech. Rock Eng., 30, 121-127, 1997.

Zhang, C.-L.: Experimental evidence for self-sealing of fractures in claystone, Phys. Chem. Earth, 36, 1972-1980, 2011. 